\title{
Ischemic Etiology of Incontinence in Women: A Theory and A Review
}

\author{
Bilal Chughtai ${ }^{1}$, Anita Mannikarottu ${ }^{1,2}$, Robert M. Levin ${ }^{*}, 1,2,3$, Paul Chichester ${ }^{2,3}$, \\ Catherine Schuler ${ }^{2,3}$, Robert E. Leggett ${ }^{2}$ and Elise De ${ }^{1}$
}

\author{
${ }^{1}$ Albany Medical Center, Albany, NY, USA \\ ${ }^{2}$ Albany College of Pharmacy, Albany, NY, USA \\ ${ }^{3}$ Stratton VA Medical Center, Albany, NY, USA
}

\begin{abstract}
Incontinence in women is a major health problem. In a recent study, incontinence affects more than 10 million Americans, $85 \%$ of whom are women. Incontinence can result in an extremely altered life style, and is the main reason that women are admitted to nursing homes. Care for the incontinent patient represents an enormous expense nationally.

The emphasis of this review is on the relevance of estrogen-dependent ischemia to urethral smooth muscle tone and tonic $\alpha$-adrenergic tension in the maintenance of continence in women. Additionally, the role of ischemia in bladder dysfunction will be explored. In general, the relative contribution of smooth muscle tension is greater in females than in males. It is clear from both animal and human data that during bladder filling there is a progressive increase in sympathetic stimulation of the urethra resulting in increased $\alpha$-adrenergic tension.
\end{abstract}

\section{INTRODUCTION}

Incontinence in women is a major health problem. In a study prepared by Yankelovich and presented by The Bladder Health Council of the American Foundation for Urologic Disease, it was stated that incontinence affects more than 10 million Americans, $85 \%$ of whom are women. It affects $20 \%$ of women over the age of 45 , the number increasing with age. Nearly $50 \%$ of all incontinence patients are dissatisfied with current treatment options, and $32 \%$ are very dissatisfied. $60 \%$ of women currently undergoing treatment report that they would try any novel therapy developed. Characterized by a high morbidity rate, incontinence is associated with a loss of self esteem, an inability to work, and is a major stress factor. It can result in an extremely altered life style, and is the main reason that women are admitted to nursing homes. Care for the incontinent patient represents an enormous expense nationally [1-4].

The emphasis of this review is on the relevance of estrogen-associated ischemia to urethral smooth muscle(SM) tone and tonic $\alpha$-adrenergic tension in the maintenance of continence in women. Additionally, the role of ischemia in bladder dysfunction will be explored. Several investigators have estimated that $30-50 \%$ of total urethral pressure is contributed by SM tone [5]. In general, the relative contribution of $\mathrm{SM}$ tension is greater in females than in males. Abdominal pressure, pelvic organ prolapse and urethral hypermobility, vascular compression, connective tissue and elastic components of the urethra can contribute to changes in urethral closure pressure [6]. It is clear from both animal and human data that during bladder filling there is a progressive increase in sympathetic stimulation of the urethra resulting in increased $\alpha$-adrenergic tension [7,8], and there is excellent direct evidence that $\alpha$-adrenergic tension is an important

*Address correspondence to this author at the Albany College of Pharmacy, 106 New Scotland Avenue, Albany, NY 12208, USA; Tel: 518-445-7306; Fax: 518-445-7248; E-mail: levinr@acp.edu factor in continence. Incontinence in general can result from urethral dysfunction, detrusor instability, detrusor insufficiency (with the resultant inability to empty effectively) and overflow incontinence. Prolapse and other anatomic findings such as urethral hypermobility can contribute to significant detrusor dysfunction and incontinence.

It is clear that in a variety of organ systems vascular insufficiency may lead to tissue changes and dysfunction. The nitric oxide pathway has been shown to allow for relaxation of SM of the corporal tissue, isolated bladder and urethral smooth muscle, and prostate. Impairment of relaxation is observed in the presence of ischemia. In addition, a reduction in circulating estrogen has been associated with urothelial and vaginal atrophy and disorders of the bladder from incontinence to increased urinary tract infections.

\section{CELLULAR MECHANISMS OF URETHRAL SMOOTH MUSCLE TONE}

Continence is dependent upon normal urethral physiology and anatomy; specifically, the maintenance of both active smooth muscle tone (i.e. the sustained response to $\alpha$ adrenergic stimulation) and the integrity of the mucosal urothelium, which forms a water-tight seal during bladder filling [3]. In men, the prostate and the well developed external striated sphincter contribute significantly to total urethral tension and continence. Women, in contrast, do not have a prostate or a well developed external striated sphincter which completely encircles the urethra, and are much more dependent upon sustained (tonic) urethral tension for continence during bladder filling. In women, mucosal atrophy during periods of reduced circulating estrogen decreases the integrity of the urethral seal during bladder filling and results in stress incontinence.

The following physiological characteristics at the level of the urethra should be directly related to an increased incidence of incontinence: a) reduced adrenergic innervation, b) reduced $\alpha$-adrenergic receptor density, c) reduced tonic response to adrenergic stimulation, d) reduced oxidative en- 
ergy generation, and e) reduced participation of sarcoplasmic reticulum(SR) $\mathrm{Ca}^{+2}$ release during adrenergic stimulation.

The level of $\alpha$-adrenergic tone is directly related to the density of adrenergic innervation and the $\alpha$-adrenergic receptor density. Metabolically, $\alpha$-adrenergic tone (sustained tension) is supported by oxidative metabolism, and is lost during periods of ischemia or hypoxia [9]. Additionally, $\alpha-$ adrenergic responses to stimulation are directly related to $\mathrm{Ca}^{+2}$ movements $\left(\mathrm{Ca}^{+2}\right.$ entry into the cell; $\mathrm{Ca}^{+2}$ uptake into the $\mathrm{SR}$, its storage and subsequent release). In this regard, we have evidence that $\mathrm{Ca}^{+2}$ release plays a major role in mediating the urethral response to both neuronal and $\alpha$-adrenergic stimulation.

Similar to all smooth muscle contraction, bladder SM contraction depends upon a rise in $\left[\mathrm{Ca}^{+2}\right]_{\mathrm{i}}[10]$ resulting from both $\mathrm{Ca}^{+2}$ influx from extracellular spaces and $\mathrm{Ca}^{+2}$ release from intracellular stores $\left(\mathrm{Ca}^{+2}\right.$-induced $\mathrm{Ca}^{+2}$ release [CICR]) [11]. In the normal bladder, $\mathrm{Ca}^{+2}$ influx is mediated primarily, if not exclusively, through L-type (dihydropyridinesensitive) $\mathrm{Ca}^{+2}$ channels; no $\mathrm{N}$ or T-type channels are believed to participate in bladder smooth muscle response to stimulation $[12,13]$.

Both extracellular $\mathrm{Ca}^{+2}$ influx and $\mathrm{Ca}^{+2}$ release from intracellular storage sites occur in response to autonomic receptor stimulation of the lower urinary tract $[14,15]$. Although most of the studies described in this body of literature relate to bladder body SM, we now have direct evidence that CICR participates to a similar or greater extent in the response of urethral smooth muscle to both field stimulation and direct $\alpha$ adrenergic stimulation by phenylephrine administration $[16$, 17]. Ovariectomy has been shown to decrease the contractile responses to field stimulation and phenylephrine, and it is believed to be through the inhibition of calcium storage and release from internal and external sites [18-20].

\section{STUDIES OF SMOOTH MUSCLE TONE}

\section{Rats}

Animal studies provide evidence that tonic $\alpha$-adrenergic stimulation is a major factor in the maintenance of continence in women. For example, a reduction in urethral pressure is observed in rats treated with alfuzosin [21]. The importance of $\alpha$-adrenergic function in the maintenance of urethral tension and continence during bladder filling is supported by this correlation between the clinical studies in women discussed below and basic studies in animals.

Smooth muscle function is altered by hormonal manipulation. Borda and co-workers found a decreased maximal response and sensitivity of contractility to prostaglandins $E_{2}$ and $E_{1}$ of bladder body strips from 20 day ovariectomized female rats compared to those from normal females [22]. Longhurst et al. observed decreased contractility of rat bladder strips in response to field stimulation and ATP two months after ovariectomy, and to field stimulation, carbachol, ATP, and $\mathrm{KCl} 4$ months after ovariectomy. The data by Longhurst et al. suggested that strip responsiveness to ATP was more sensitive to loss of sex hormones than was responsiveness to muscarinic agonists. The ovariectomyinduced changes were prevented by estradiol replacement [23]. Ovariectomy and estrogen replacement studies show conflicting results, likely due to varying doses and prepara- tions of estrogen, different time-courses and different species.

\section{Rabbits}

\section{Autonomic Receptors}

There are many studies examining changes in autonomic receptors in the lower urinary tract after ovariectomy and/or estrogen treatment; like the contractility data, results are conflicting. However, all agree that affinity of autonomic ligands for their receptors does not change. Polyestradiol treatment of mature female rabbits causes increased alphareceptor density in the urethra [24], but estradiol treatment of immature females has no effect on alpha-, beta-, or muscarinic receptor density in the rabbit bladder base [25]. Similarly, Shapiro found that neither ovariectomy nor estradiol treatment affects muscarinic receptor density in the female rabbit urethra/base compared to mature, intact controls [26]. Three separate studies on autonomic receptors in the rabbit bladder body present conflicting results. Levin et al. found that estradiol treatment of immature female rabbits caused increases in bladder body alpha- and muscarinic receptor densities, but no change in beta-receptor density [27]. Shapiro found no change in bladder muscarinic receptor density after ovariectomy, and a decrease after ovariectomy + estradiol treatment [26]. Batra and Andersson ovariectomized rabbits and then, after 2 weeks, treated them with estradiol polyphosphate [28]. They observed a decreased muscarinic receptor density after ovariectomy, which was not reversed by estradiol treatment. These conflicting data may be the result of different concentrations and timings of hormonal manipulations.

\section{Urethral Mass}

Studies showing that estradiol treatment increases bladder and urethra mass $[29,30]$ support clinical findings of increased urethral mucosa thickness in postmenopausal women after estrogen therapy [16, 31, 32].

\section{Detrusor Contractility}

Studies examining the effects of hormone treatment on bladder contractile function have produced conflicting results. Short-term (4 days) high-dose treatment of immature female rabbits with estradiol caused increased contractile responses of bladder body strips to epinephrine, ATP, methoxamine, and bethanechol compared to immature intact controls [27, 30]. However, Batra and Andersson found no change in sensitivity or maximal contractile response to field stimulation or carbachol of bladder strips from female rabbits treated with estradiol polyphosphate for up to 8 weeks compared to ovariectomized controls [28].

\section{Blood Flow}

In recent studies in our lab we have demonstrated that ovariectomy results in a significant decrease in blood flow to the bladder mucosa and detrusor using both quantitative measurement via fluorescent microspheres, and using realtime laser Doppler methodologies. The decreased blood flow is correlated with mucosal hypoxia, mucosal apoptosis, and mucosal and detrusor smooth muscle atrophy, and increased mucosal permeability. Estrogen administration to ovariectomized rabbits resulted in the relief of hypoxia, mucosal hyperplasia and restoration of the mucosal permeability bar- 
rier [33-39]. Specifically, in our chronic studies [33, 34, 36], female rabbits were divided into three groups. The rabbits in group 1 received sham operations (Shm), group 2 received ovariectomies (Ovx) for two weeks, and group 3 received ovariectomies + estrogen therapy at $1 \mathrm{mg} / \mathrm{kg} /$ week via Alzet pump $(\mathrm{Ovx}+\mathrm{E})$ beginning 1 week following ovariectomy and continuing for 5 weeks. At 6 weeks following ovariectomy various studies were performed on 6-8 rabbits per group. The results can be summarized as follows: Ovx resulted in: 1) a significant decrease in bladder weight 2) significant decrease in blood flow to the bladder mucosa and smooth muscle (Fig. 1A); corresponding with a decreased vascular density (Fig. 1B); 3) a thinning of the bladder mucosa. 4) a decrease in the smooth muscle / connective tissue ratio resulting in a decreased compliance. 5) decreased contractile responses to field stimulation, carbachol, and $\mathrm{KCl}$, whereas estrogen administration resulted in a significant increase in contractile responses. 6) Ovx induced a generalized hypoxia of the mucosa and submucosal elements, which were reversed by estrogen administration (Fig. 2). 7) Ovx stimulated mucosal and submucosal apoptosis, and increased mucosal permeability. 8) Ovx resulted in atrophy of the bladder smooth muscle, whereas estrogen administration resulted in significant hypertrophy of the smooth muscle (Fig. 3) and mucosal hyperplasia. 9) Ovx resulted in an increased incidence of uninhibited contractions observed during cystometry (personal observation).

In a study recently published, we looked at the effects of cycling estrogen from low to high by first performing a bilateral ovariectomy; at two weeks we began estrogen administration via the implantation of a slow release tablet (1 $\mathrm{mg} / \mathrm{kg} /$ day). At the end of two weeks estrogen administration we removed the tablet to create a second period of low estrogen. At the end of two weeks, the estrogen tablet was restored for a second period of estrogen administration. The results demonstrated a cyclical effect on bladder weight and urethral thickness (Fig. 4). Histologically, in both muscle and mucosal compartments, there was a cyclical shift from atrophy (during low estrogen periods) to hypertrophy (muscle) and hyperplasia (mucosa) during high estrogen periods [36]. Similar results were observed for vascular density
(A)

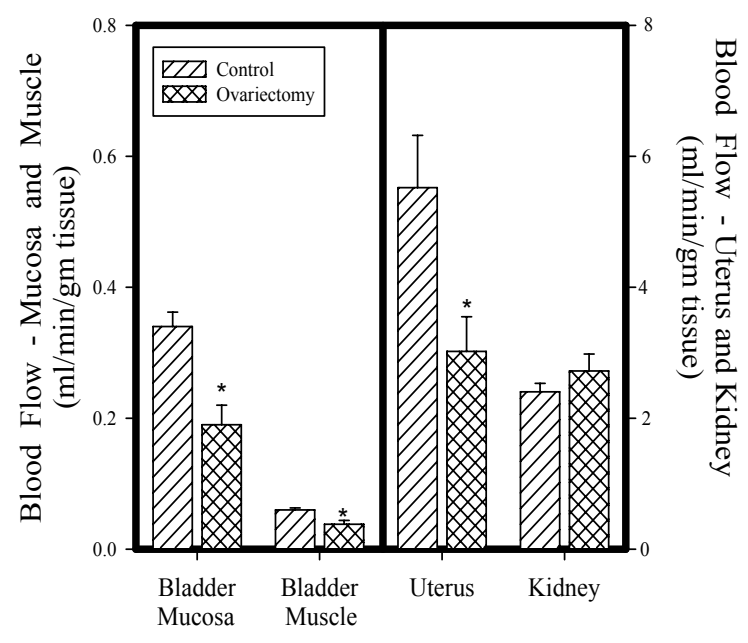

(B)

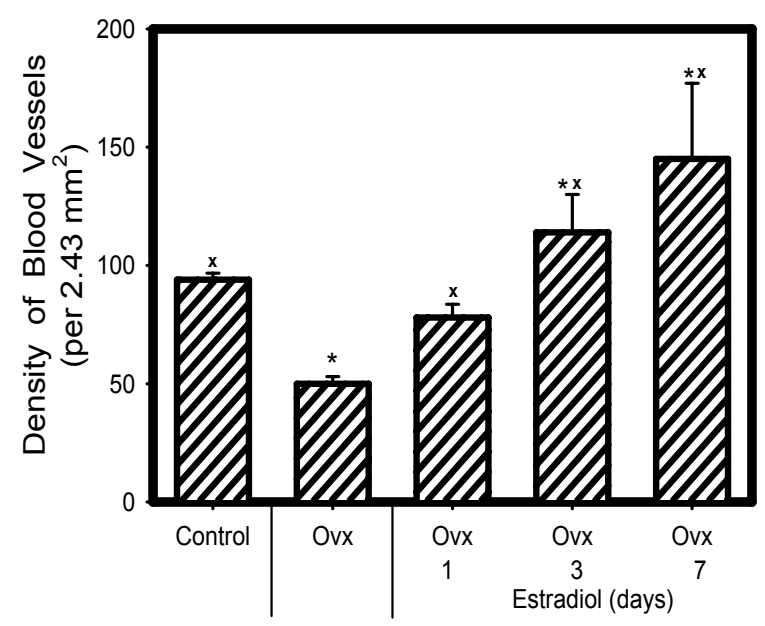

Fig. (1). Effect of Ovx on blood flow (A). Estrogen supplementation restored both blood flow and vascularity to control levels within 7 days (B). Each bar is the mean +/- SEM of 4-6 individual rabbits. $*=$ significantly different from control; $\mathrm{x}=$ significantly different from Ovx.
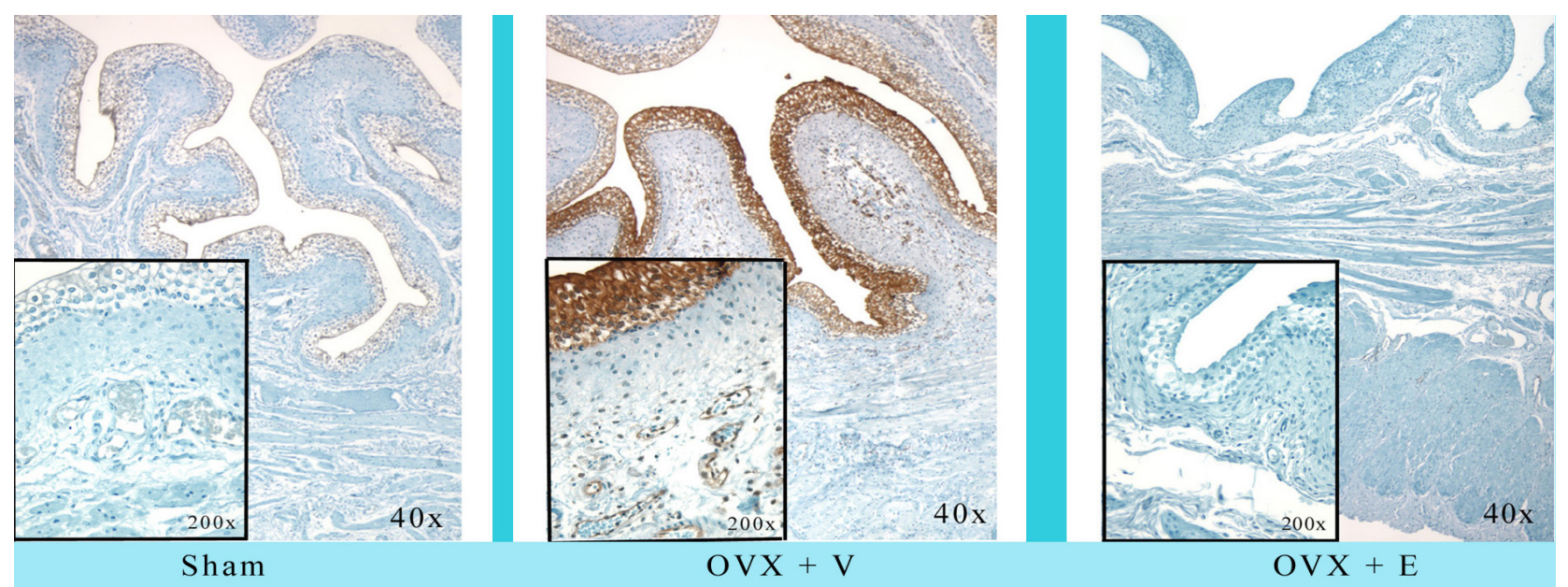

Fig. (2). Effect of Ovx and Ovx + estrogen on hypoxia using hypoxyprobe-1 immunohistochemistry. Ovx resulted in diffuse hypoxia within the mucosa and submucosa; estrogen reversed the hypoxia completely. Reduced from $40 \mathrm{X}$. 


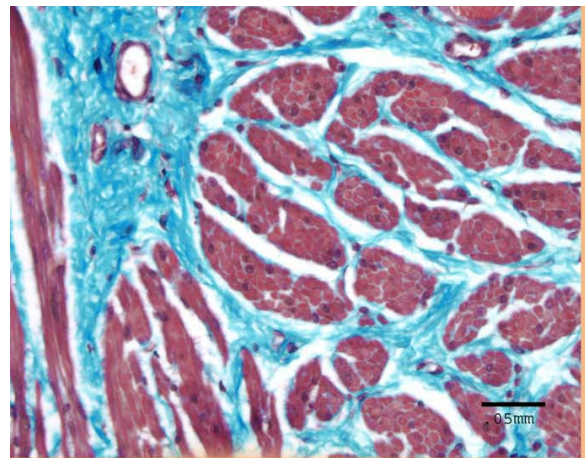

Ovariectomy

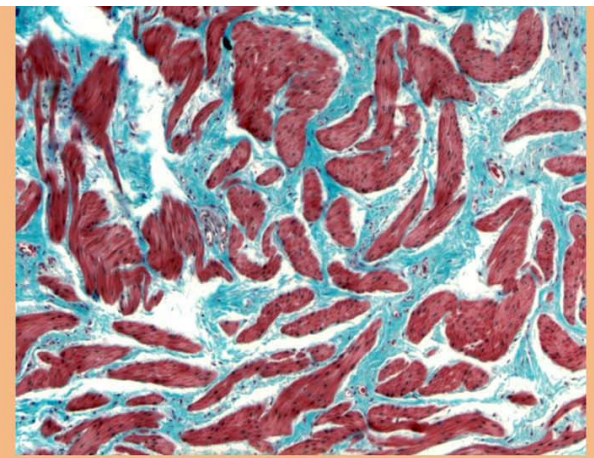

Normal

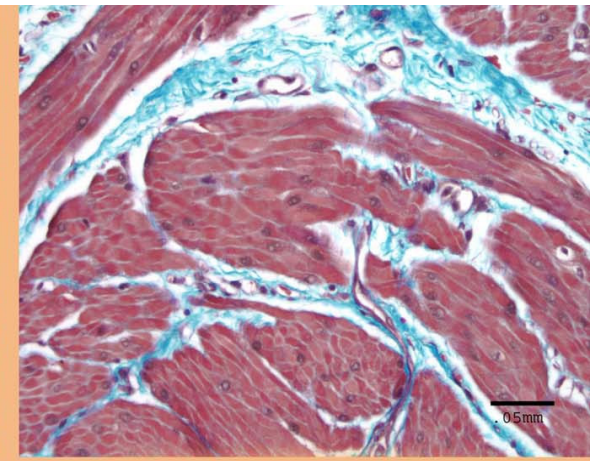

Ovx with estradiol

Fig. (3). Effect of Ovx and ovx + estrogen on bladder structure. Ovariectomy resulted in atrophy of the smooth muscle compartment whereas estrogen administration resulted in significant hypertrophy of the smooth muscle. Reduced from 200X.

(Fig. 5) for the bladder body; however, the vascular density for the urethra did not change. Similar results were shown for the smooth muscle / collagen ratio. That is, for the bladder body there was a clear cycling; the ratio significantly decreased during low estrogen periods and significantly increased during periods of high estrogen (Fig. 6).

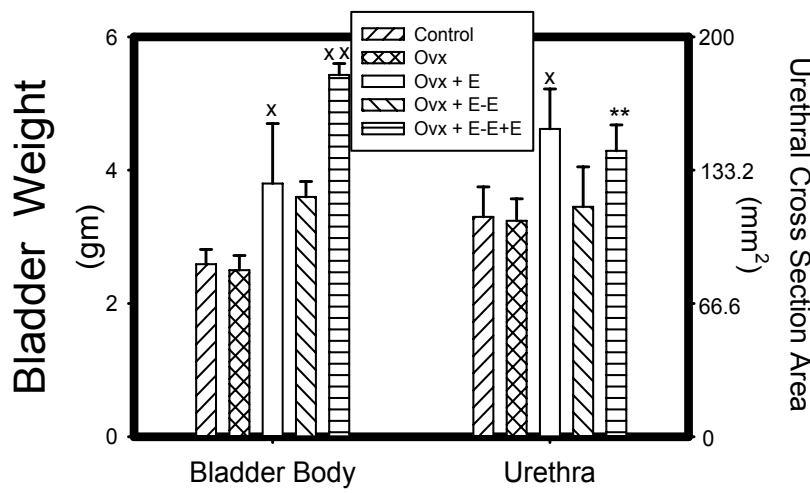

Fig. (4). Effect of cyclical estrogen on bladder mass and urethral cross sectional area. Each bar is the mean +/- SEM of 4-6 individual rabbits. $\mathrm{x}=$ significantly different from control; $\mathrm{xx}=$ significantly different from ovx $+\mathrm{E} ; * *=$ significantly different from ovx + E - E. $p<0.05$.

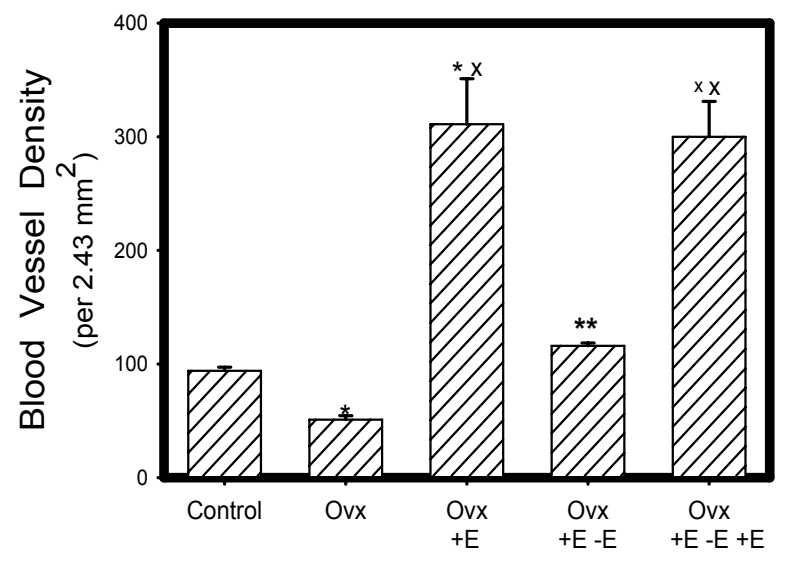

Fig. (5). Effect of cyclical estrogen on vascular density. Each bar is the mean $+/-$ SEM of 4-6 individual rabbits. ${ }^{*}=$ significantly different from control; $\mathrm{x}=$ significantly different from ovx; $* *=$ significantly different from ovx $+\mathrm{E} ; \mathrm{xx}=$ significantly different from ovx $+\mathrm{E}-\mathrm{E} ; \mathrm{p}<0.05$.

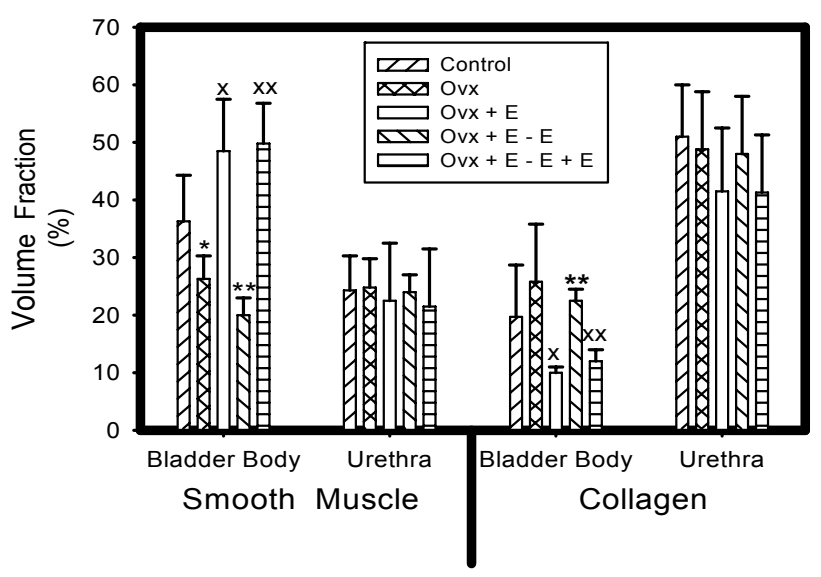

Fig. (6). Effect of cyclical estrogen on smooth muscle - collagen ratio. Each bar is the mean +/- SEM of 4-6 individual rabbits. * = significantly different from control; $\mathrm{x}=$ significantly different from ovx; $* *=$ significantly different from ovx $+\mathrm{E} ; \mathrm{xx}=$ significantly different from ovx $+E-E ; p<0.05$.

Our studies demonstrate clearly that ovariectomy (reduced circulating estrogen) resulted in decreased blood flow to the mucosa and to a lesser extent to the smooth muscle, hypoxia of the mucosa, submucosa, and vascular endothelium, apoptosis, atrophy of the smooth muscle compartment and increased collagen deposition, decreased compliance, increased permeability of the urothelium, contractile dysfunction and an increased incidence of uninhibited contractions.

\section{CLINICAL STUDIES}

\section{Autonomic Receptors}

Varied human clinical studies support the role of smooth muscle tone and function in incontinence. There is a considerable base of clinical evidence in men and women which demonstrates that $\alpha$-adrenergic stimulation (especially using chronic slow-release therapy) increases both maximal urethral pressure (MUP) and maximal urethral closure pressure (MUCP), significantly reducing both stress and sphincteric incontinence. Specifically, Diokno and Taub reported that ephedrine sulfate treatment was effective for sphincteric incontinence in 27 out of 38 patients [40]. Awad et al. demonstrated that norepinephrine administration resulted in a sig- 
nificant increase in both MUP and MUCP [41]. Several clinical studies have demonstrated that the $\alpha$-agonist, phenylpropanolamine, is an effective therapeutic agent for stress and sphincteric incontinence [42,43]. Alternately, there is considerable evidence that anti-hypertensive therapy with $\alpha$ adrenergic antagonists, such as prazosin, can induce moderate to severe stress incontinence [42-45]. In normal healthy women, prazosin administration resulted in a significant reduction in urethral closure pressure [46]. Terazosin produces lower urethral closure pressure in human females [47].

\section{Estrogen and Progesterone}

It is clear that estrogen plays a role in both the lower urinary tracts of animal models and human models. Estrogen and progesterone receptors have been shown to be present in the lower urinary tract, vagina, and pelvic musculature. The female genital and lower urinary tracts both arise from the urogenital sinus and are both sensitive to the effects of sex steroid hormones. Deficiency of estrogen as found in menopause leads to atrophy of the urethra, bladder, etc. [48]. This has been found to be associated with urinary frequency, nocturia and infection, although the exact role is unclear. The effects of estrogen therapy vary according to the route of administration, systemic therapy improves incontinence episodes and first sensation to void, however it appeared to worsen nocturia. As opposed to local estrogen therapy, which seems improves frequency, urgency, urge incontinence, first sensation to void, and bladder capacity [48, 49].

Both androgen and progesterone receptors are expressed in the lower urinary tract. Progesterone receptors have been reported in the bladder, trigone, and vagina, although their presence may depend on estrogen status. Androgen receptors are present in both the bladder and urethra. The role of both these receptors has not yet been elucidated. The mechanism of estrogen may include the following: (1) increasing urethral resistance, (2) raising the sensory threshold of the bladder, (3) increasing $\alpha$-adrenoreceptor sensitivity in the urethral smooth muscle (although animal data exists to the contrary above), and (4) promoting $\beta_{3}$ adrenoceptor-mediated relaxation of the detrusor muscle [48]. In one study, it was found that in women estrogen treatment influences collagen synthesis and directly affects collagen metabolism in the lower genital tract. The composition of collagen composition also changes [49].

If manipulating hormone levels in animals alters lower urinary tract blood flow and function, one wonders whether physiologic cycling of estrogen contribute to voiding dysfunction over the years. In other organ systems it is clear that alterations in the level of circulating hormones that occur normally in women can alter mucosal and smooth muscle function. For example, asthma is significantly more prevalent among women and women are affected more severely by asthma than are men [50-52]. Asthma has been shown to be significantly more severe immediately prior to menses and less severe immediately after menses. In a recent study by Skobeloff, severity of asthma was directly compared with plasma levels of estrogen and progesterone [53]. The results demonstrate that the symptoms of asthma were least severe during the sustained high estrogen levels observed during the post-ovulatory period and substantially more severe during the low-estrogen period immediately pre-ovulatory period.
Although the etiology of asthma is not fully understood, there is a definite relationship between asthma and inflammatory stimulation of the bronchial mucosal surface.

Mucosal cell structure and metabolism are under direct hormonal control (estrogen and progesterone). The normal alterations in women's hormonal levels could potentially increase mucosal sensitivity to stresses such as distension, ischemia, and hypoxia. Experimentally, it has been long recognized that alterations in sex hormones can have profound effects on smooth muscle and mucosal structure and function, in that female factors lead to variable responses in otherwise well controlled animal experiments [54-56]. The basic strategy used to "normalize" these hormone-induced alterations has been simply to exclude females from scientific studies, both at the experimental (animal) and clinical levels. As mentioned above, recent studies in our lab have confirmed the marked effects of alterations in estrogen on bladder mucosal structure and properties in rabbits [33-39]. The following is a brief discussion of the effects of hormonal alterations on lower urinary tract function.

In nulliparous premenopausal women, it has been found that there is a mid-cycle and early luteal-phase increase in the functional urethral length as measured by urethral pressure profile [57]. This occurs in tandem with increased plasma estradiol. The vascular supply to the lower urinary tract plays a significant role in providing urinary continence to women. As mentioned previously, the major target for ischemia and hypoxia is cellular metabolism. Blood flow to the lower urinary tract, as well as to the vagina and uterus, can be affected significantly by alterations in estrogen and progesterone $[58,59]$. Estrogen has been shown to increase blood flow to the bladder and urethra whereas progesterone can block this effect $[60,61]$. The demonstration that blood flow can be modulated by alterations in sex hormones, together with the finding by Irwin and Galloway that blood perfusion is reduced during distension in IC patients [62], support the importance of reduced blood flow in this genderrelated disorder. In a study of 17 awake male patients who underwent saline cystoscopy while undergoing analysis of bladder blood flow by laser doppler flow of the posterior bladder wall. It was found that at capacity bladder blood flow is significantly decreased. After bladder drainage, there is rebound blood flow and reperfusion, suggesting bladder ischemia leads to architectural changes of the bladder wall [63]. Also, in a study by Tsai et al., it was found that women who were on transdermal hormone replacement therapy were found to have decreased vascular impedance on Duplex Doppler Ultrasonography of the uterine, internal carotid, ophthalmic and bladder wall arteries [64]. In a study on young women with recurrent urinary tract infections (UTI), application of local estrogen cream lead to decreased resistive indices and increased end diastolic blood flow velocity in 2 bladder arteries as compared to before starting the treatment. These patients were also found to have an increase of the infection-free period between UTIs. In a follow-up period of 11 months after treatment, 24/30 patients reported no symptoms of cystitis [65].

Estrogen reduction during menopause induces mucosal atrophy and other degenerative changes affecting bladder and urethral function, which can be at least partially reversed by estrogen therapy $[16,31,32]$. Functionally, mucosal atro- 
phy might increase the susceptibility of post-menopausal women to urinary tract infections due to disruption of the mucosal barrier [66]. In addition, yeast and bacterial adherence to buccal and other mucosal surfaces have been shown to be significantly altered during the menstrual cycle $[60,61$, 67].

In a meta analysis by Cardozo et al., 11 randomized controlled studies on over active bladder and the effect of either systemic or local estrogens were analyzed. Overall, estrogens (local and systemic therapy) were associated with alleviating symptoms of overactive bladder. Systemic estrogen therapy only had a significant improvement in nocturnal frequency but is associated with worsening nocturia as opposed to vaginal estrogen which shows benefit in all symptoms analyzed [49].

Maintenance of the integrity of the mucosa is dependent upon cellular metabolism. Although there are no studies on the effects of hormonal alterations on bladder mucosal metabolism, there is information on the effects of female sex hormones on both gastrointestinal and buccal mucosal metabolism and cellular function. Gastric enzyme synthesis and secretions, and buccal enzyme synthesis and activities are modulated by alterations in estrogen and progesterone levels during menses [68-71]. The demonstration that alterations in estrogen and progesterone can significantly affect mucosal cellular metabolism, enzyme synthesis and secretion, and metabolic function is relevant to the hypothesis that urothelial metabolism and cellular function can be significantly altered by altered circulating levels of these hormones. Azpiroz et al. described dysuria in Irritable Bowel Syndrome (IBS) patients and Cukier et al. found patient with IBS were more likely to experience nocturia, urgency, and some forms of urinary urge incontinence $[72,73]$. The ultimate effect on lower urinary tract function is yet to be characterized.

\section{Ageing}

As mentioned previously, incontinence associated with ageing is a major health problem $[1,2]$. In a study by Lepor et al. in 1993, they found that the AUA symptom score of both aging men and women, ages $59-79$, worsened as they aged [74]. This may be related to pelvic ischemia. We hypothesize that incontinence (in relation to ageing) is in part related to a generalized decrease in the metabolic energy available to sustain urethral tone, in addition to the postmenopausal hormonal alterations which occur in women. Reduced energy supply causes a progressive decrease in the tonic response of the urethra, the loss of $\alpha$-adrenergic tonic tension, and a decreased urethral pressure, resulting in incontinence. The increased smooth muscle "fatigue" is concurrent with changes in the detrusor's ability to empty the bladder completely; the resultant progressively increasing residual volume is also associated with the effects of ischemia on lower urinary tract function. As women age, flow rate, voided volume, and bladder capacity decrease and post void residual urine increases. This is suggestive of increasing fibrosis of the bladder wall with aging. Maximum isometric detrusor pressure and maximum pressure at peak flow are found to be preserved. Female urethral pressures are also found to decrease with age [75]. Supporting this supposition are the studies by Lin et al. who demonstrated that in ageing rats there was a progressive decrease in the contractile re- sponses to repetitive autonomic stimulation (increase in fatigue) which was directly associated with both a decrease in the metabolic energy available to support the contractile responses, and a decrease in mitochondrial enzyme activities $[76,77]$. Thus, in association with ageing, there is a progressive reduction in the rate of high energy phosphate generation (during periods of stimulation) that significantly increases the rate of fatigue of the bladder smooth muscle. Previously, we demonstrated a significantly reduced ability of isolated whole bladders from aged rabbits (as compared to those from young rabbits) to generate pressure and empty efficiently. The rate of power generation, the percent emptying, and the amount of work performed by bladders from old rabbits were significantly less than bladders from young rabbits. In addition, there was a marked reduction in the ability of the bladders isolated from old rabbits to respond to an increase in outlet resistance [78, 79]. Our studies support the theory that ageing is associated with a progressive reduction in the ability of the bladder to sustain increased tension.

\section{CONCLUSIONS}

The overall conclusion from the studies reviewed is that modulation of circulating female sex hormones (especially estrogen) can have profound effects on bladder and urethral structure, mass, blood flow, tissue oxygenation, autonomic receptor density, distribution, and responses. The evidence is growing that ovariectomy induces hypoxia and ischemia and that hypoxic/ischemic damage to bladder nerves, smooth muscle, and the mucosa can result in significant bladder dysfunction [80]. We further hypothesize that physiologic cycling of estrogen can lead to cyclic ischemia, leading to lower urinary tract dysfunction and incontinence. Acute ischemia from childbirth, chronic ischemia related to vascular disease or hormonal withdrawal in menopause can also play a role.

\section{ACKNOWLEDGEMENTS}

This material is based upon work supported in part by the Office of Research and Development Medical Research Service, Department of Veteran's Affairs, and in part by NIH grant RO-1-DK 067114, and in part by Capital Region Medical Research Foundation.

\section{REFERENCES}

[1] Dubeau CE. The aging lower urinary tract. J Urol 2006; 175 (3 Pt 2): S11-15.

[2] McGuire EJ. Pathophysiology of incontinence in elderly women, In: Geriatric Medicine. Edited by P. D. Odonnel MD. New York: Little, Brown, and Company, 1994; pp. 221-228.

[3] Molander U, Milsom L, Ekiund P, Melistrom D. An epidemiological study of urinary incontinence and related urological symptoms in elderly women. Maturitas 1990; 12: 51-55.

[4] Lawhorne LW, Ouslander JG, Parmelee PA, Resnick B, Calabres B. Urinary incontinence: a neglected geriatric syndrome in nursing facilities. J Am Med Dir Assoc 2008; 9(1): 29-35.

[5] Awad SA, Downie JW. Relative contributions of smooth and striated muscles to urethral pressure profile. Br J Urol 1976; 48: 347 50 .

[6] Tanagho EA, Meyers FH, Smith DR. Urethral resistance: Its components and implications: I Smooth muscle component. Invest Urol 1969; 7: 136-140.

[7] Steers WD. Physiology of the urinary bladder. In: Cambells Urology. Edited by P. C. Walsh, A. B. Retik, T. A. Stamey and E. D. Vaughan, Jr. Philadelphia: Saunders, pp. 142-176, 1992.

[8] Wein M, Levin RM, Barrett DM. Voiding function: Relevant anatomy, physiology, and pharmacology. In: Adult and Pediatric Urol- 
ogy. Edited by J. Y. Gillenwater, J. T. Grayhack, S. S. Howards and J. D. Duckett, Chicago: Year Book Medical Publishers, 2nd ed. 1991; pp. 933-999.

[9] Kwon H-Y, Wein AJ, Levin, RM. Effect of anoxia on the urethral response to phenylephrine. J Urol 1995; 154: 1527-1531.

[10] Fovaus M, Andersson K-E, Batra S, Morgan E, Sjogren C. Effects of calcium, calcium channel blockers, and Bay K8644 on contractions induced by muscarinic receptor stimulation of isolated bladder muscle from rabbit and man. J Urol 1987; 137: 798-803.

[11] Mostwin JL. Receptor-operated intracellular calcium stores in the smooth muscle of guinea-pig bladder. J Urol 1985; 900-905.

[12] Isenberg G, Wendt-Gallitelli, Ganitkevich, V. Contribution of $\mathrm{Ca}^{2+}$ induced release to depolarization-induced $\mathrm{Ca}^{2+}$ transients of myocites from guinea-pig urinary bladder myocytes. Jpn J Pharmacol 1992; 58: (Suppl 2) 81P-86P.

[13] Brading, AF. Ion channels and control of contractile activity in urinary bladder smooth muscle. Jpn J Pharmcol 1992 58: (Suppl 2) 120P-127P.

[14] Batra S, Sjogren C, Andersson K-E, Fovaeus M. Source of calcium for contraction induced by depolarization and muscarinic receptor stimulation in rabbit urinary bladder. Acta Physiol Scand 1987; 130: 545-551.

[15] Maggi CA, Manzini S, Parlani M, Conte B, Giuliani S, Meli A. The effect of nifedipine on spontaneous, drug induced and reflexlyactivated contractions of the rat urinary bladder: evidence for the participation of an intracellular calcium store to micturition contraction. Gen Pharmacol 1988; 19: 73-81.

[16] Levin RM, Longhurst PA. Pharmacological basis of bladder and urethral function in the female. In Female Urology (Raz S, Ed.) W.B. Saunders Co., The Curtis Center, Philadelphia, Pa. 1996; pp. 43-56.

[17] Schroeder A, Lieb J, O'Connor L, Horan P, Leggett R, Levin RM. Role of calcium and calcium modulation in the control of urethral tone. Scand J Urol Nephrol Suppl 2001; 207: 19-25.

[18] Batra S. Effect of estrogen and progesterone treatment on calcium uptake by the myometrium and smooth muscle of the lower urinary tract. Eur J Pharmacol 1986; 127: 37-42.

[19] Batra S. Interaction of antiestrogens with binding sites for muscarinic cholinergic drugs and calcium channel blockers in cell membranes. Cancer Chemother Pharmacol 1990; 26: 310-312.

[20] Eika B, Salling LN, Christensen LL, Andersen A, Laurberg S, Danielsen CC. Long-term observation of the detrusor smooth muscle in rats. Its relationship to ovariectomy and estrogen treatment. Urol Res 1990 18: 439-444.

[21] Martin D, Jammes D, Angel I. Effects of Alfuzosin on urethral and blood pressures in conscious male rats. Life Sci 1995; 57: 25, PL387-391.

[22] Borda E, Chaud M, Gutnisky R, et al. Relationships between prostaglandins and estrogens on the motility of isolated rings from the rat urinary bladder. J Urol 1983; 129: 1250-1255.

[23] Longhurst PA, Kauer J, Leggett RE, Levin RM. The influence of ovariectomy and estradiol replacement on urinary bladder function in rats. J Urol 1992; 148: 915- 919.

[24] Larsson B, Andersson K-E, Batra S, Mattiasson A, Sjögren C. Effects of estradiol on norepinephrine-induced contraction, alpha adrenoceptor number and norepinephrine content in the female rabbit urethra. J Pharmacol Exp Ther 1984; 229: 557-561.

[25] Yamaguchi T, Kitada S, Osada Y. Role of adrenoceptors in the proximal urethral function of female and male rabbits using an in vivo model of isovolumetric pressure generation. Neurourol Urodyn 1993; 12: 49-53.

[26] Shapiro E. Effect of estrogens on the weight and muscarinic cholinergic receptor density of the rabbit bladder and urethra. J Urol 1986; 135: 1084-1088.

[27] Levin RM, Jacobowicz D, Wein AJ: Autonomic innervation of rabbit bladder following estrogen administration. Urology 1981; 17: 449-453.

[28] Batra S, Andersson K-E. Oestrogen-induced changes in muscarinic receptor density and contractile responses in the female rabbit urinary bladder. Acta Physiol Scand 1989; 137: 135-139.

[29] Batra SC, Iosif CS. Female urethra: A target for estrogen action. J Urol 1983; 129: 418-422.

[30] Levin RM, Shofer FS, Wein AJ. Estrogen-induced alterations in the autonomic responses of the rabbit urinary bladder. J Pharmacol Exp Ther 1980; 215: 614-619.
[31] Elia G, Bergman A. Estrogen effects on the urethra: Beneficial effects in women with genuine stress incontinence. Obstet Gynecol 1993; 48: 509-517.

[32] Schoultz B. Estrogens and urogenital epithelial function. Acta Obstet Gynecol Scand Suppl 140: 28-32.

[33] Aikawa K, Sugino T, Matsumoto S, Chichester P, Whitbeck C, Levin RM. The Effect of Ovariectomy and Estradiol on Rabbit Bladder Smooth Muscle Contraction and Morphology. J Urol 2003; 170: 634-637.

[34] Parekh MH, Chichester PC, Lobel RW, Levin RM. Effects of castration on female rabbit bladder physiology and morphology. Urology 2004; 64: 1048-1051.

[35] Badger WJ, Whitbeck C, Kogan B, Chichester P, Levin RM. The Immediate Effect of Castration on Female Rabbit Bladder Blood Flow and Tissue Oxygenation. 2006; Urol Int 76: 264-268.

[36] Palmieri K, Mannikarottu A, Chicester P, et al. The Effects of Cyclical Estrogen on Bladder and Urethral Structure and Function. BJU Int 2007; 99: 171 - 176.

[37] Lin A, Levin R, Kogan B, et al. Alteration of Contractile and Regulatory Proteins in Estrogen-induced Hypertrophy of female rabbit bladder. Urology 2006; 68(5): 1139-1143.

[38] Lin A, Levin R, Whitbeck C, et al. Estrogen induced functional hypertrophy of the female rabbit bladder. Neurourol Urodyn 2006; 25(5): 473-479.

[39] Lin A, Mannikarottu A, Kogan B, et al. Estrogen induces angiogenesis of the female rabbit bladder. J of Endocrinology 2006; Aug 190(2): 241-246

[40] Diokno S, Taub M. Ephedrine in treatment of urinary incontinence. Urology 1975; 5: 624-628.

[41] Awad SA, Andersson KE, Gullberg B. The effects of long term treatment with norephedrine on stress incontinence and urethral closure pressure profile. Scand J Urol Nephrol 1978; 12: 105-110.

[42] Awad SA, Downie J, Kiruluta, H. Alpha adrenergic agents in urinary disorders of the proximal urethra: I: Stress incontinence. BJU Int 1978; 50: 332-335.

[43] Stewart B, Borowsky L, Montague D. Stress incontinence: conservative therapy with sympathomimetic drugs. J Urol 1976; 115: 558-561.

[44] Wall LL, Addison WA. Prazosin-induced stress incontinence. Obstet Gynecol 1990; 75: 558-560.

[45] Dwyer PL, Teele JS. Prazosin: a neglected cause of genuine stress incontinence. Obstet Gynecol 1992; 79: 117-121.

[46] Thind P, Lose G, Colstrup H, Andersson KE. The effect of alphaadrenoceptor stimulation and blockade on the static urethral sphincter function in healthy females. Scand J Urol Nephrol 1992; 26: 219-225.

[47] Kessler TM, Studer UE, Burkhard FC. The effect of terazosin on functional bladder outlet obstruction in women: a pilot study J Urol 2006; 176 (4 Pt 1): 1487-1492.

[48] Robinson D, Cardozo LD. The Role of Estrogens in Female Lower Urinary Tract Dysfunction. Urology 2003; 62 (4 Suppl 1): 45-51.

[49] Cardozo L, Gunnar L, McClish, D, Versi E. A systematic review of the effects of estrogens for symptoms suggestive of overactive bladder. Acta Obstet Gynecol Scand 2004; 83: 892-897.

[50] Skobeloff EM, Spivey WH, Clair S, Schoffstall JM. The influence of age and sex on asthma admissions. JAMA 1992; 268: $3437-$ 3440.

[51] Dodge RR, Burrows B. The prevalence and incidence of asthma and asthma-like symptoms in a general population sample. Am Rev Respir Dis 1980; 122: 567-575.

[52] Pauli BD, Reid RL, Munt PW. Influence of the menstrual cycle on airway function in asthmatic and normal subjects. Am Rev Respir Dis 1989; 140: 358-362.

[53] Skobeloff EM, Spivey WH, Silverman R, Eskin BA, Harchelroad F, Alessi TV. The effect of the menstrual cycle on asthma presentations in the emergency department. Arch Intern Med 1996; 156: 1837-1840.

[54] Roberts JM, Insel PA, Goldfien RD, Goldfien A. Alpha receptors but not beta receptors increase in rabbit uterus with oestrogen. Nature 1977; 270: 624-627.

[55] Raz S, Zeigler M, Caine M. The effect of progesterone on the adrenergic receptors of the urethra. BJU Int 1973; 45: 131-135.

[56] Blakeman PJ, Hilton P, Bulmer JN. Cellular proliferation in the female lower urinary tract with reference to oestrogen status. BJOG 2001; 108: 813-816. 
[57] van Geelen JM, Doesburg WH. Thomas CM, Martin CB Jr. Urodynamic studies in the normal menstrual cycle: the relationship between hormonal changes during the menstrual cycle and the urethral pressure profile. Am J Obstet Gynecol 1981; 141;384-392.

[58] Batra S, Bjellin L, Iosif S, Mårtensson L, Sjögren C. Effect of oestrogen and progesterone on the blood flow in the lower urinary tract of the rabbit. Acta Physiol Scand 1985; 123: 191-194.

[59] Batra S, Bjellin L, Sjögren C, Iosif S, Widmark E. Increases in blood flow of the female rabbit urethra following low dose estrogens. J Urol 1986; 136: 1360-1362.

[60] Kalo A, Segal E. Interaction of Candida albicans with genital mucosa: effect of sex hormones on adherence of yeasts in vitro. Can $\mathrm{J}$ Microbiol 1988; 34: 224-227.

[61] Theaker ED, Drucker DB, Gibbs AC. The possible influence of the menstrual cycle on the adherence of candida albicans to human buccal epithelial cells in vitro. Arch Oral Biol 1993; 38: 353-355.

[62] Irwin P, Galloway NM. Impaired bladder perfusion in interstitial cystitis: A study of blood supply using laser doppler flowmetry. J Urol 1993; 149: 890-892.

[63] Kershen R, Azadzoi K, Siroky M. Blood Flow Pressure and Compliance in the Male Human Bladder. J Urol 2002; Vol. 168, 121125.

[64] Tsai E, Yang C, Chen H, Wu C, Lee J. Bladder Neck Circulation by Dopplar Ultrasonography in Post Menopausal Women with Urinary Stress Incontinence. Obstet Gynecol 2001; 98(1): 52-56.

[65] Pinggera GM, Feuchtner G, Frauscher F, et al. Effects of local estrogen therapy on recurrent urinary tract infections in young females under oral contraceptives. Eur Urol 2005; 47(2): 243-249.

[66] Altoparlak U, Kadanali A, Kadanali S. Correlation of urinary tract infections with the vaginal colonization in postmenopausal women. Mikrobiyol Bul 2004; 38(4): 377-383.

[67] Winkler J, Block C, Leibovici L, Faktor J, Pitlik SD. Nasal carriage of staphylococcus aureus: Correlation with hormonal status in women. Concise Commun JIK 1990; 162: 1400-1402.

[68] Tiwari B, Ganeriwal, SK, Athawale VR. Oral epithelial alkaline phosphatase in various phases of menstrual cycle. Ind J Physiol Pharmac 1984; 28: 149-152.
[69] Black HE. The effects of steroids upon the gastrointestinal tract. Toxicol Path 1988; 16: 213-222.

[70] Neonakis E, Vasssilakis JS, Xynos E, Kittas C, Androulakis G. Fundic, antral and pancreatic D-cell population changes following oophorectomy and sex hormone administration in guinea pigs. Eur Surg Res 1988; 20: 144-148.

[71] Vidic B, Kapur SP, Jenkins DP. Estrogen and tracheal secretion: The effect of estrogen on the epithelial secretory cells of the rat trachea. Cytobiologie 1970; 10: 10-21.

[72] Azpiroz F, Dapoigny M, Pace F, et al. Nongastrointestinal disorders in the irritable bowel syndrome. digestion 2000; 62(1): 66-72.

[73] Cukier JM, Cortina-Borja M, Brading AF. A case-control study to examine any association between idiopathic detrusor instability and gastrointestinal tract disorder, and between irritable bowel syndrome and urinary tract disorder. BJU Int 1997; 79(6): 865-878.

[74] Lepor H, Machi G. Comparison of AUA symptom index in unselected males and females between fifty-five and seventy-nine years of age. Urology 1993; 42(1): 36-40; discussion 40-41.

[75] Siroky MB. The Aging Bladder. Rev Urol 2004; 6(Suppl 1): S3-712.

[76] Lin AT, Yang C, Chang LS. Impact of aging on rat urinary bladder fatigue. J Urol 1997; 157: 1990-1994.

[77] Lin AT, Hsu TH, Yang C, Chang LS. Effects of aging on mitochondrial enzyme activity of rat urinary bladder. Urol Int 2000; 65: 144-147.

[78] Yu HJ, Levin RM, Longhurst PA, Damaser MS. Effect of age and outlet resistance on rabbit urinary bladder emptying. J Urol 1997; 158: 924-930.

[79] Damaser MS, Yu HJ, Longhurst PA, Levin RM. The concept of bladder work: Work and power in bladder emptying. Scand J Urol Neph Suppl 1997; 184: 35-41.

[80] Yoshida J, Aikawa K, Yoshimura Y, Shishido K, Yanagida T, Yamaguchi $O$. The effects of ovariectomy and estrogen replacement on acetylcholine release from nerve fibres and passive stretch-induced acetylcholine release in female rat bladder. Neurourol Urodyn 2007; 26(7): 1050-1055. 